\title{
Survey of HIV mothers in Botswana: Feeding methods, support, status disclosure and infant testing
}

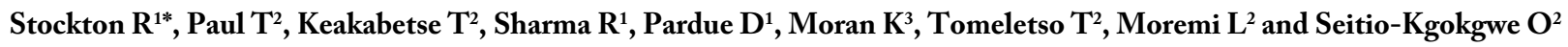 \\ ${ }^{1}$ Indiana University, 201 North Rose Ave, Bloomington, Indiana 47405, USA \\ ${ }^{2}$ Institute for Development Management Botswana Africa \\ ${ }^{3}$ Indiana University Purdue University
}

\begin{abstract}
A survey of HIV positive mothers in Botswana, Africa, all enrolled in a PMTCT programme, was conducted. A total of 305 mothers from randomly selected sites volunteered and completed the survey related to infant feeding, disclosure of HIV status, infant testing, and support from family and clinic services. The majority of mothers used formula feeding (64\%) with their infants and almost half of the mothers indicated that they believed breastfeeding to be unsafe. The majority of mothers reported having disclosed their HIV status to partners and family and felt they had benefited from having done so. Social stigma did not appear to be a significant concern for the mothers in this study. Overall, mothers were very positive concerning the support they received from partners, family, and medical/clinic services. HIV testing was reported for 178 babies with 5 (3\%) found to be positive for HIV. A discussion of the findings, along with recommendations for areas needing further study and attention, is provided.
\end{abstract}

\section{Introduction}

In accordance with the 2000 United Nations recommendations on breastfeeding, Botswana National PMTCT Guidelines were revised and endorsed exclusive formula feeding for the first 6 months of life, with introduction of breastfeeding thereafter; provided that this option is acceptable, feasible, affordable, sustainable, and safe, commonly dubbed the AFASS criterion (WHO, UNICEF, UNAIDS, 2000). To support this recommendation, the government of Botswana, through the Ministry of Health, provided free infant formula for up to twelve months of life. However, in 2010 WHO recommendations changed to favour breastfeeding along with mothers continuing ART treatment throughout a six-month exclusive breastfeeding period (WHO, UNAIDS, UNICEF, UNFPA, 2010).

Botswana has had a successful Prevention of Mother to Child Transmission (PMTCT) Programme with a testing uptake of $98 \%$, ART uptake of $96 \%$ and a mother-to-child transmission (MTCT) rate ranging between $3-4 \%$. However, there has been a low testing rate $(47 \%)$ of HIV-exposed babies at 6-8 weeks old despite the fact that HIV testing of babies is routinely offered as part of antenatal care, delivery, and postnatal care services of the PMTCT process (Ministry of Health, PMTCT Program DATA, 2015). HIV prevalence among pregnant women in Botswana remains high at $30.4 \%$ and a high percentage of mothers (93.5\%) who test positive are enrolled into the PMTCT program.

It is important to note that almost all paediatric HIV infections occur through mother-to-child transmission during pregnancy, childbirth or breastfeeding. Breastfeeding has been associated with HIV transmission rates of $35 \%-45 \%$ in developing countries [1,2]. Additionally, studies done in Nairobi [3] and Uganda [4] reported increased rates of HIV transmission through breastfeeding [5]. However, babies who are not breastfed stand a higher risk of morbidity and mortality due to other causes such as malnutrition, pneumococcal infection and diarrhoea. This has created a dilemma for HIV positive mothers regarding whether to breastfeed and expose babies to HIV infection or formula feed and risk a greater chance of new-born mortality from other causes [6].

Traditionally there is high premium placed on breastfeeding in developing countries especially within the African context (Botswana included), [5,7]. Even with evidence linking mother to child transmission through breastfeeding some mothers have been very reluctant to practice formula feeding. Due to the stigma associated with HIV infection, formula feeding has been perceived as "forced" disclosure of HIV status, as women who opted to formula feed were believed to be HIV positive. Moreover, studies have also indicated that there are other determinants that pressure women to opt for a particular infant feeding pattern. Some women have reported pressure from service providers [8], partners or caregivers [7] and other sociocultural or economic factors [5].

Ndubuka et al. [6] note that AIDS related stigma poses a significant barrier to the uptake of formula feeding in Botswana. A study by Stockton [9] observed a tendency among women in Botswana to hide their status from significant others. This lack of disclosure has a bearing on the uptake of recommended PMTCT services including patterns of infant feeding as well as infant testing. Disclosure rates to sexual partners have been found to be higher (16-86\%) for women who attend voluntary testing and counselling clinics than women tested at antenatal clinics (ANC). Among the ANC tested women, an average of $8 \%$ of

${ }^{\star}$ Correspondence to: Stockton R, Department of Counseling and Educational Psychology, Indiana University Bloomington, IN 47405, USA, E-mail: Stocktor@indiana.edu

Key words: breastfeeding, formula feeding, disclosure, support, infant testing, Botswana, PMTCT

Received: June 15, 2018; Accepted: June 21, 2018; Published: June 30, 2018 
women reported a violent reaction from partners upon disclosure, thus having implications on optimal adherence to infant feeding practices [10]. To address infant feeding practices among HIV positive mothers, it is therefore imperative to use a multifaceted approach addressing socio-cultural and related determinants of decision making among these women. This study sought to assess the infant feeding patterns of HIV positive mothers and disclosure to family, partners or care givers in an effort to better understand mothers' infant feeding decisions and practices.

WHO's 2013 guidelines recommended that a woman living with HIV be provided with lifelong treatment, regardless of CD4 count, for their own medical benefit. This is termed Option B+ of HIV/AIDS management. As Botswana moves towards implementation of option $\mathrm{B}+$ in order to eliminate MTCT of HIV, understanding of mothers' infant feeding patterns including knowledge, attitudes and practices is crucial. It is against this background that the Institute of Development Management (IDM) carried out a study to fill this knowledge gap. The Institute of Development Management (IDM) was established in 1974 by the governments of Botswana, Lesotho and Swaziland to provide training, consultancy, and research services to government, parastatal and private organizations. The institution has grown tremendously over time in scope and capacity to provide the aforementioned services.

As a response to the HIV/AIDS epidemic, the Government of Botswana established the National AIDS Coordinating Agency (NACA). The overall purpose of NACA is to develop and support partnerships, harmonize, coordinate and facilitate implementation of the national response to HIV and AIDS.

The current study focuses on women enrolled in the PMTCT programme, including their decisions and perceptions related to infant feeding, infant testing, support systems, and HIV status disclosure to significant others. The results of the current study should prove useful in developing pragmatic interventions and healthcare practices that better address the barriers to prevention of mother to child transmission of HIV.

\section{Method}

\section{Participants}

Inclusion criteria required respondents to be enrolled in the PMTCT program, to be at least 18 years of age, HIV positive, and to have given birth to a live child within the past 6 months. The average age of the 305 respondents was 30.38 years ( $S D=6.25)$; 198 were single, 32 married, 71 cohabitating, 3 divorced, and 1 widowed. The numbers of participants who reported their highest level of education were as follows: 7 no formal education, 3 non-formal education, 38 primary education, 208 secondary education, and 49 post-secondary education. The current employment status of the respondents included 207 unemployed, 55 salaried employees, 14 part-time employees, and 28 self-employed ( 1 missing value). Formula feeding was used by 196 (64\%) of the mothers, breastfeeding by 106 (35\%) mothers, and mixed formula and breastfeeding by 3 (1\%) mothers.

\section{Survey instrument}

A survey instrument was developed for the study. Based on the advice of Botswana colleagues and officials, the survey was composed in English since it is one of the two national languages in Botswana and is taught in the schools.

The survey included the following sections: participant information, baby's health, mother's health, infant feeding intentions/practices, disclosure to partner/family, and a 25 item Likert-type rating section. Participants were encouraged to respond to as many questions as possible, but to skip any questions that did not apply to their situation or that they felt uncomfortable answering.

\section{Procedure}

The study was approved by the Ministry of Health in Botswana (Health Research and Development Committee). Informed consent information was provided to volunteer respondents in English or Setswana based on the preference of the participant. Participants were informed of the study rationale, were assured that participation was voluntary, and were informed of the limits of confidentiality.

Volunteer participants were recruited from randomly selected clinics from city, town, urban, and rural areas. The sites included Gaborone, Selebi Phikwe, Lobatse, Mahalapye, Boteti/Letlhakane and Ghanzi districts. Trained employees of the Institute for Development Management (IDM), an institution in Botswana training HIV/AIDS paraprofessional counsellors, traveled to each of the selected clinic sites and explained the study and consent procedure to potential participants. Those who agreed to participate signed a consent form and were given a survey instrument to complete.

\section{Results}

Respondents reported participating in the PMTCT program for an average of 9.82 months ( $S D=4.79)$. The average age of the mothers' children, born while in the PMTCT program, was 3.27 months (SD $=1.69)$. A total of $249(82 \%)$ mothers indicated that their child had been tested for HIV though only 178 (58\%) mothers reported HIV test results for their child; 173 children (97\%) were negative and $5(3 \%)$ were positive for HIV. A total of 187 (61\%) participants reported that they had begun ARV treatment before becoming pregnant with 118 (39\%) beginning treatment after becoming pregnant. A total of 106 (35\%) participants indicated that they used exclusive breastfeeding, 196 (64\%) reported exclusive formula feeding, and 3 (1\%) reported mixed breast and formula feeding. A total of 290 (95\%) participants indicated that their partner knew of their HIV positive status while 15 (5\%) reported that their partner did not know of their status. A total of 289 (94\%) participants reported that their family members knew of their HIV status while 16 (5\%) indicated that their family did not know of their status.

PMTCT participants' responses to the 25 Likert-type items were analyzed by calculating the frequency and percentage of respondents who rated each item across the five "Strongly Disagree-Strongly Agree categories. These data are presented in Table 1 with items grouped under the original six item categories used in constructing the instrument (item numbers refer to the order of the items on the survey) (Table 1).

Six survey items assessed participants' reactions to having disclosed their HIV status. Overall, respondents were very positive regarding their experience with disclosing their HIV status. They were particularly positive (Agreeing or Strongly Agreeing) concerning having been honest about their HIV status with their partner (92\%), regarding disclosure as beneficial (95\%) and finding they could be more open seeking help and advice after disclosing (97\%). They were also very positive in their responses to one negatively worded item with $92 \%$ Disagreeing or Strongly Disagreeing that they regretted disclosing their HIV status to family/spouse. Although most participants responded positively to the remaining two items concerning disclosure, the percentages were somewhat lower with $68 \%$ Agreeing or Strongly Agreeing that infant feeding became less challenging as a result of disclosure and $72 \%$ 
Table 1. Survey item response category frequencies and percentages

Items by Category

\section{Disclosure of HIV Status}

8. I have been completely honest about my HIV status with my partner.

9. Disclosing my HIV status was beneficial.

12. I regret disclosing my status to my family/spouse.

13. After disclosure I can seek help and advice more openly.

14. Infant feeding has become less challenging as a result of disclosure.

17. I did not want to disclose the HIV status because of social stigma.

\section{Support}

10. My spouse was supportive and sympathetic after learning of my HIV status.

11. My family was supportive of me, knowing my HIV status.

16. My family was not supportive of getting my baby tested.

18. My husband is not supportive of getting our baby tested.

24. My family/spouse is supportive of my feeding decision.

\section{Medical Advice}

4. I seek medical advice regularly.

5. The medical advice has been useful

22. The medical advice regarding infant feeding was helpful in maintaining my feeding decision.

\section{Infant Feeding}

I find it safe to breastfeed my child.

20. I wanted to make an informed decision about feeding my baby.

23. My baby is safe and healthy because of the right feeding decisions.

25. The social stigma made it difficult to formula fee my infant.

\section{Clinic Services}

I find the guidelines given by the clinic useful.

My clinic has helped in making breast feeding safer for my child.

21. My clinic was supportive of my situation and I felt safe seeking help.

\section{Child Testing}

15. I was scared to get my baby tested for HIV

19. I got motivated to get infant testing done because I wanted my child to be safe.

6. My breast feeding pattern changed after seeking medical advice

7. The medical advice has not been useful in making my feeding decision.

\begin{tabular}{|c|c|c|c|c|}
\hline \multicolumn{5}{|c|}{ Responses } \\
\hline SD & D & $\mathbf{A} / \mathbf{D}$ & $\mathbf{A}$ & S/A \\
\hline $\begin{array}{c}6 \\
2.0 \%\end{array}$ & $\begin{array}{c}11 \\
3.6 \%\end{array}$ & $\begin{array}{c}7 \\
2.3 \%\end{array}$ & $\begin{array}{c}95 \\
31.1 \%\end{array}$ & $\begin{array}{c}186 \\
61.0 \%\end{array}$ \\
\hline $\begin{array}{c}3 \\
1.0 \%\end{array}$ & $\begin{array}{c}2 \\
0.7 \%\end{array}$ & $\begin{array}{c}11 \\
3.6 \%\end{array}$ & $\begin{array}{c}99 \\
32.5 \%\end{array}$ & $\begin{array}{c}189 \\
62.0 \%\end{array}$ \\
\hline $\begin{array}{c}167 \\
54.8 \%\end{array}$ & $\begin{array}{c}113 \\
37.0 \%\end{array}$ & $\begin{array}{c}5 \\
1.6 \%\end{array}$ & $\begin{array}{c}10 \\
3.3 \%\end{array}$ & $\begin{array}{c}10 \\
3.3 \%\end{array}$ \\
\hline $\begin{array}{c}3 \\
1.0 \%\end{array}$ & $\begin{array}{c}1 \\
0.3 \%\end{array}$ & $\begin{array}{c}4 \\
1.3 \%\end{array}$ & $\begin{array}{c}119 \\
39.0 \%\end{array}$ & $\begin{array}{c}178 \\
58.4 \%\end{array}$ \\
\hline $\begin{array}{c}24 \\
7.9 \%\end{array}$ & $\begin{array}{c}52 \\
17 \%\end{array}$ & $\begin{array}{c}21 \\
6.9 \%\end{array}$ & $\begin{array}{c}97 \\
31.8 \% \\
\end{array}$ & $\begin{array}{c}111 \\
36.4 \%\end{array}$ \\
\hline $\begin{array}{c}98 \\
32.1 \%\end{array}$ & $\begin{array}{c}122 \\
40.0 \%\end{array}$ & $\begin{array}{c}37 \\
12.1 \%\end{array}$ & $\begin{array}{c}27 \\
8.9 \%\end{array}$ & $\begin{array}{c}21 \\
6.9 \%\end{array}$ \\
\hline SD & D & $\mathbf{A} / \mathbf{D}$ & A & $\mathbf{S} / \mathbf{A}$ \\
\hline $\begin{array}{c}16 \\
5.2 \%\end{array}$ & $\begin{array}{c}16 \\
5.2 \%\end{array}$ & $\begin{array}{c}7 \\
2.3 \%\end{array}$ & $\begin{array}{c}88 \\
28.9 \% \\
\end{array}$ & $\begin{array}{c}178 \\
58.4 \%\end{array}$ \\
\hline $\begin{array}{c}11 \\
3.6 \%\end{array}$ & $\begin{array}{c}13 \\
4.3 \%\end{array}$ & $\begin{array}{c}11 \\
3.6 \%\end{array}$ & $\begin{array}{c}90 \\
29.5 \%\end{array}$ & $\begin{array}{c}180 \\
59.0 \%\end{array}$ \\
\hline $\begin{array}{c}144 \\
47.2 \%\end{array}$ & $\begin{array}{c}104 \\
34.1 \%\end{array}$ & $\begin{array}{c}32 \\
10.5 \%\end{array}$ & $\begin{array}{c}10 \\
3.3 \%\end{array}$ & $\begin{array}{c}15 \\
4.9 \%\end{array}$ \\
\hline $\begin{array}{c}142 \\
46.6 \%\end{array}$ & $\begin{array}{c}99 \\
32.5 \%\end{array}$ & $\begin{array}{c}22 \\
7.2 \%\end{array}$ & $\begin{array}{c}23 \\
7.5 \%\end{array}$ & $\begin{array}{c}19 \\
6.2 \%\end{array}$ \\
\hline $\begin{array}{c}3 \\
1.0 \%\end{array}$ & $\begin{array}{c}1 \\
0.3 \%\end{array}$ & $\begin{array}{c}10 \\
3.3 \%\end{array}$ & $\begin{array}{c}119 \\
39.0 \%\end{array}$ & $\begin{array}{c}172 \\
56.4 \%\end{array}$ \\
\hline SD & D & $\mathbf{A} / \mathbf{D}$ & A & S/D \\
\hline $\begin{array}{c}4 \\
1.3 \% \\
\end{array}$ & $\begin{array}{c}6 \\
2.0 \%\end{array}$ & $\begin{array}{c}3 \\
1.0 \%\end{array}$ & $\begin{array}{c}137 \\
44.9 \%\end{array}$ & $\begin{array}{c}155 \\
50.8 \%\end{array}$ \\
\hline $\begin{array}{c}3 \\
1.0 \%\end{array}$ & $\begin{array}{c}2 \\
0.7 \%\end{array}$ & $\begin{array}{c}6 \\
2.0 \%\end{array}$ & $\begin{array}{c}94 \\
30.8 \%\end{array}$ & $\begin{array}{c}200 \\
65.6 \%\end{array}$ \\
\hline $\begin{array}{c}4 \\
1.3 \%\end{array}$ & $\begin{array}{c}1 \\
0.3 \%\end{array}$ & $\begin{array}{c}5 \\
1.6 \%\end{array}$ & $\begin{array}{c}120 \\
39.3 \%\end{array}$ & $\begin{array}{c}175 \\
57.4 \%\end{array}$ \\
\hline SD & D & $\mathbf{A} / \mathbf{D}$ & A & $\mathbf{S} / \mathbf{D}$ \\
\hline $\begin{array}{c}84 \\
27.5 \%\end{array}$ & $\begin{array}{c}58 \\
19.0 \%\end{array}$ & $\begin{array}{c}30 \\
9.8 \%\end{array}$ & $\begin{array}{c}75 \\
24.6 \%\end{array}$ & $\begin{array}{c}58 \\
19.0 \%\end{array}$ \\
\hline $\begin{array}{c}1 \\
0.3 \%\end{array}$ & $\begin{array}{c}0 \\
0.0 \%\end{array}$ & $\begin{array}{c}3 \\
1.0 \%\end{array}$ & $\begin{array}{c}126 \\
41.3 \%\end{array}$ & $\begin{array}{c}175 \\
57.4 \%\end{array}$ \\
\hline $\begin{array}{c}1 \\
0.3 \%\end{array}$ & $\begin{array}{c}2 \\
0.7 \%\end{array}$ & $\begin{array}{c}16 \\
5.2 \%\end{array}$ & $\begin{array}{c}97 \\
31.8 \%\end{array}$ & $\begin{array}{c}189 \\
62.0 \%\end{array}$ \\
\hline $\begin{array}{c}137 \\
44.9 \%\end{array}$ & $\begin{array}{c}118 \\
38.7 \%\end{array}$ & $\begin{array}{c}25 \\
8.2 \%\end{array}$ & $\begin{array}{c}12 \\
3.9 \%\end{array}$ & $\begin{array}{c}13 \\
4.3 \%\end{array}$ \\
\hline SD & D & $\mathbf{A} / \mathbf{D}$ & A & $\mathbf{S} / \mathbf{A}$ \\
\hline $\begin{array}{c}5 \\
1.6 \%\end{array}$ & $\begin{array}{c}3 \\
1.0 \%\end{array}$ & $\begin{array}{c}5 \\
1.6 \%\end{array}$ & $\begin{array}{c}131 \\
43.0 \%\end{array}$ & $\begin{array}{c}161 \\
52.8 \%\end{array}$ \\
\hline $\begin{array}{c}41 \\
13.4 \%\end{array}$ & $\begin{array}{c}49 \\
16.1 \%\end{array}$ & $\begin{array}{c}35 \\
11.5 \%\end{array}$ & $\begin{array}{c}98 \\
32.1 \%\end{array}$ & $\begin{array}{c}82 \\
26.9 \%\end{array}$ \\
\hline $\begin{array}{c}1 \\
0.3 \%\end{array}$ & $\begin{array}{c}0 \\
0.0 \%\end{array}$ & $\begin{array}{c}4 \\
1.3 \% \\
\end{array}$ & $\begin{array}{c}121 \\
39.7 \%\end{array}$ & $\begin{array}{c}179 \\
58.7 \%\end{array}$ \\
\hline SD & D & $\mathbf{A} / \mathbf{D}$ & A & $\mathbf{S} / \mathbf{A}$ \\
\hline $\begin{array}{c}113 \\
37.0 \%\end{array}$ & $\begin{array}{c}77 \\
25.2 \%\end{array}$ & $\begin{array}{c}24 \\
7.9 \%\end{array}$ & $\begin{array}{c}48 \\
15.7 \%\end{array}$ & $\begin{array}{c}43 \\
14.1 \%\end{array}$ \\
\hline $\begin{array}{c}1 \\
0.3 \%\end{array}$ & $\begin{array}{c}2 \\
0.7 \%\end{array}$ & $\begin{array}{c}3 \\
1.0 \%\end{array}$ & $\begin{array}{c}96 \\
31.5 \%\end{array}$ & $\begin{array}{c}203 \\
66.6 \%\end{array}$ \\
\hline $\begin{array}{c}89 \\
29.2 \% \\
\end{array}$ & $\begin{array}{c}110 \\
36.1 \%\end{array}$ & $\begin{array}{c}32 \\
10.5 \%\end{array}$ & $\begin{array}{c}49 \\
16.1 \%\end{array}$ & $\begin{array}{c}25 \\
8.2 \%\end{array}$ \\
\hline $\begin{array}{c}133 \\
43.6 \%\end{array}$ & $\begin{array}{c}132 \\
43.3 \%\end{array}$ & $\begin{array}{c}8 \\
2.6 \%\end{array}$ & $\begin{array}{c}12 \\
3.9 \%\end{array}$ & $\begin{array}{c}20 \\
6.6 \%\end{array}$ \\
\hline
\end{tabular}

Note: $\mathrm{SD}=$ Strongly Disagree; $\mathrm{D}=$ Disagree; $\mathrm{A} / \mathrm{D}=$ Neither Agree nor Disagree; A = Agree; $\mathrm{SA}=$ Strongly Agree. $\mathrm{N}=305$ except for item 9 that had one missing value. Within each category, items are listed in order of their original survey item numbers.

Disagreeing or Strongly Disagreeing to the negatively worded item indicating that they did not want to disclose their HIV status due to social stigma.

Five items assessed participants' support from their family or spouse. For the three positively worded items $87 \%$ of the participants Agreed or Strongly Agreed that their spouse was supportive and sympathetic after learning of their HIV status, $89 \%$ Agreed or Strongly Agreed that their family was supportive knowing their HIV status, and 95\% Agreed or Strongly Agreed that their family/spouse was supportive of their feeding decision. For the two negatively worded items $81 \%$ Disagreed or Strongly Disagreed that their family was not supportive of getting their baby tested for HIV and 79\% Disagreed or Strongly 
Disagreed that their husband was not supportive of getting their baby tested.

Four positively worded items and one negatively worded item assessed participants' reactions to the medical advice they had received. The majority of participants (65\%) Disagreed or Strongly Disagreed with the positively worded item stating that their breastfeeding pattern changed after seeking medical advice while only 24\% Agreed or Strongly Agreed with this item. The remaining three positively worded items were rated Agree or Strongly Agree by the vast majority of participants; $96 \%$ indicated they sought medical advice regularly, $96 \%$ rated the medical advice they received as useful, and $97 \%$ indicated that the medical advice they received was helpful in maintaining their infant feeding decision. For the negatively worded item, $87 \%$ of participants Disagreed or Strongly Disagreed that medical advice had not been useful in making feeding decisions.

Three positively worded items and one negatively worded item assessed participants' reactions to their infant feeding method. More participants (47\%) Disagreed or Strongly Disagreed with the positively worded item stating that they found it safe to breastfeed than did those who Agreed or Strongly Agreed (44\%) with this item. The vast majority of participants Agreed or Strongly Agreed with the remaining two positively worded items; $99 \%$ indicated they wanted to make an informed decision about feeding their baby and $94 \%$ agreed that their baby was safe and healthy because of the right feeding decision. Responses to the one negatively worded item indicated that $84 \%$ of participants Disagreed or Strongly Disagreed that social stigma made it difficult to formula feed their infant.

Three positively worded items assessed participants' ratings of clinic services. The majority of respondents Agreed or Strongly Agreed with each of these three items with $96 \%$ finding the guidelines given by the clinic as useful and $98 \%$ indicating that the clinic was supportive of their situation and that they felt safe seeking help. A smaller percentage of participants (59\%) Agreed or Strongly Agreed that their clinic helped in making breast feeding safer for their child while 30\% Disagreed or Strongly Disagreed with this statement.

One negatively worded and one positively worded item assessed participants' ratings regarding infant testing for HIV. Responses to the negatively worded item indicated that $62 \%$ of participants Disagreed or Strongly Disagreed that they were scared to have their baby tested for HIV while 30\% Agreed or Strongly Agreed with this statement. Responses indicated that $98 \%$ of participants Agreed or Strongly Agreed that they were motivated to have their child tested because they wanted their child to be safe.

A second stage of data analyses utilized Principal Component Analysis (PCA) to determine if meaningful components could be identified among the 25 Likert-type items. PCA seeks to reduce a high dimensional data-set to a smaller number of components. This data reduction procedure groups items into components that are measuring the same construct and makes it possible to derive single scores for each component [11].

Participants' responses to the Strongly Disagree-Strongly Agree scales were converted to a numerical 1-5 (Strongly Disagree-Strongly Agree) scale for the PCA. Normality was assessed using skewness and kurtosis statistics, and linearity was examined through scatter plots. There was no compelling reason to transform the data to improve normality. Pairwise deletion of missing data was used for the analysis and the negatively worded items in the survey were reversed scored.
Principal Component Analysis with Promax (oblique) rotation provided the most interpretable component structure (Kaiser-MeyerOlkin measure of sampling adequacy $=.78$; Bartlett's test of sphericity significant at .00). Three components were identified with eigenvalues above 1.00 and with at least three items with Cronbach alpha levels deemed strong enough for further analysis. Table 2 displays the rotated component matrix values for items included in each of the three components selected for further analysis

The four items in the first component focused on participants' satisfaction with clinic support and with the medical advice they had received, this component was named "Satisfaction with Clinic and Medical Advice" (SATISFACTION). The second component included three items focused on the level of participants' support from their spouse or partner and was named "Spouse/Partner Support" (SPOUSE/ PARTNER SUPPORT). The third component included four items primarily focused on the benefits of disclosing participants' HIV status and was named "Benefits of Disclosing HIV Status" (BENEFITS OF DISCLOSURE).

The alpha internal consistency coefficients for the three components were as follows: SATISFACTION = .73; SPOUSE/PARTNER SUPPORT $=.75$; and BENEFITS OF DISCLOSURE $=.62$. The validity of these scales, for the purpose of this study, is supported by the fact that the items within each component were similar in focus and each component closely matched with the topic categories the instrument was designed to assess, thus supporting the face validity and construct validity of the scales.

Component-based scores were derived by averaging the items within each component with negatively worded items reverse scored. Component scores for each participant could range from 1 (Strongly Disagree) to 5 (Strongly Agree) with higher scores indicating more positive/favorable ratings for all three components. Table 3 displays the means, standard deviations and zero-order intercorrelations among the three component scores.

The component scores had low to moderate intercorrelations with SATISFACTION and SPOUSE/PARTNER SUPPORT correlated at .20, SATISFACTION and BENEFITS OF DISCLOSURE at .36, and SPOUSE/PARTNER SUPPORT and BENEFITS OF DISCLOSURE at .35. Additional analyses explored for possible relationships among the three component scores and selected demographic and related variables of the study using correlation and ANOVA procedures.

Table 2. Component structures for survey items

\begin{tabular}{|l|c|c|c|}
\hline & $\mathbf{1}$ & 2 & 3 \\
\hline 4. I seek medical advice regularly. & $\mathbf{. 8 2}$ & .19 & .27 \\
\hline 5. The medical advice has been useful & $\mathbf{. 8 2}$ & .08 & .21 \\
\hline 2. I find the guidelines given by the clinic useful. & $\mathbf{. 6 0}$ & .09 & .42 \\
\hline $\begin{array}{l}\text { 21. My clinic was supportive of my situation and I felt safe seeking } \\
\text { help. }\end{array}$ & $\mathbf{. 5 6}$ & .25 & .50 \\
\hline 8. I have been completely honest about my HIV status with my partner. & .17 & $\mathbf{. 8 4}$ & .25 \\
\hline $\begin{array}{l}\text { 10. My spouse was supportive and sympathetic after learning of my } \\
\text { HIV status. }\end{array}$ & .15 & $\mathbf{. 8 2}$ & .39 \\
\hline \begin{tabular}{l|c|} 
18. My husband is not supportive of getting our baby tested. \\
13. After disclosure I can seek help and advice more openly.
\end{tabular} & .11 &. $\mathbf{7 4}$ & .24 \\
\hline 9. Disclosing my HIV status was beneficial. & .18 & $\mathbf{. 7 3}$ \\
\hline 11. My family was supportive of me, knowing my HIV status. & .24 & .48 & $\mathbf{. 6 7}$ \\
\hline
\end{tabular}

Note: Boldface coefficients indicate the highest loading for each item. The three Identified components are titled (from 1-3 respectively) satisfaction with clinic and medical advice (Satisfaction); spouse/ partner support (Spouse/Partner Support); and benefits of disclosing HIV Status (Benefits of Disclosure). 
Table 3. Means, Standard Deviation and intercorrelations among components scores

\begin{tabular}{|l|c|c|c|c|c|}
\hline \multicolumn{1}{|c|}{ Variable } & \multicolumn{5}{|c|}{ Components } \\
\hline 1. Satisfaction & M & SD & $\mathbf{1}$ & $\mathbf{2}$ & $\mathbf{3}$ \\
\hline 2. Spouse/ Partner Support & 4.51 & .50 & -- & $.20^{*}$ & $.36^{*}$ \\
\hline 3. Benefits of Disclosure & 4.27 & .86 & & -- & $.35^{*}$ \\
\hline
\end{tabular}

Note: Satisfaction $=$ Satisfaction with Clinic and Medical Advice; Spouse/Partner Support $=$ Spouse/Partner Support; And Benefits of Disclosure = Benefits of Disclosing HIV Status. $* \mathrm{p}<.01$

No significant correlations were found between the component scores and participants' age, time enrolled in the PMTCT program, or children's ages at the time of the survey. ANOVA comparisons revealed no significant differences between the various categories of participants' highest education level, employment status, or feeding method practiced across any of the three component scores.

The comparison of participants who indicated their pregnancy was wanted $(\mathrm{n}=217)$ versus those indicating their pregnancy was not wanted $(n=88)$ revealed significant differences related to SPOUSE/ PARTNER SUPPORT, $\mathrm{F}(1,303)=5.90, \mathrm{P}<.05, \mathrm{\eta} 2=.02$, and BENEFITS OF DISCLOSURE, $\mathrm{F}(1,303)=6.52, \mathrm{p}<.05, \mathrm{\eta} 2=.02$. Participants indicating their pregnancy was wanted rated SPOUSE/PARTNER SUPPORT $(\mathrm{M}=4.35, \mathrm{SD}=.80)$ and BENEFITS OF DISCLOSURE $(\mathrm{M}$ $=4.54, \mathrm{SD}=.55)$ more positively than did participants indicating their pregnancy was not wanted $(\mathrm{M}=4.08, \mathrm{SD}=.99$ and $\mathrm{M}=4.35, \mathrm{SD}=.64$ respectively).

The comparison of participants who began ARV treatment before becoming pregnant $(n=187)$ with those who began treatment after becoming pregnant $(n=118)$ revealed a difference related to SPOUSE/ PARTNER SUPPORT, $\mathrm{F}(1,303)=4.15, \mathrm{p}<.05, \mathrm{\eta} 2=.01$. Participants who began treatment before becoming pregnant $(\mathrm{M}=4.35, \mathrm{SD}=.75)$ rated

SPOUSE/PARTNER SUPPORT more positively than did those beginning treatment after becoming pregnant $(\mathrm{M}=4.14, \mathrm{SD}=1.00$.

Participants were asked if they had taken their ARV medication as directed. Those who were not at all sure or somewhat sure ( $\mathrm{n}=$ 111) were compared across the three component scores with those who were very or extremely sure $(\mathrm{n}=190)$. Significant differences were found for SATISFACTION, F $(1,299)=33.12, \mathrm{p}<.01, \mathrm{\eta} 2=.10$, SPOUSE/PARTNER SUPPORT, $\mathrm{F}(1,299)=25.34, \mathrm{p}<.01, \mathrm{\eta} 2=.08$, and BENEFITS OF DISCLOSURE, $\mathrm{F}(1,299)=37.56, \mathrm{p}<.01, \mathrm{\eta} 2=.11$. Participants who were very or extremely sure had higher ratings than did those who were not at all or somewhat sure for SATISFACTION $(\mathrm{M}=4.63$ and 4.30 respectively), SPOUSE/PARTNER SUPPORT (M $=4.45$ and 3.95 respectively), and BENEFITS OF DISCLOSURE $(\mathrm{M}=$ 4.64 and 4.24 respectively).

Participants indicating that their partner knew their HIV status ( $n=290$ ) were compared across the component scores with those indicating their partner did not know their status $(\mathrm{n}=15)$. A significant difference was found between the two groups for SPOUSE/PARTNER SUPPORT, $\mathrm{F}(1,303)=142.02, \mathrm{p}<.01, \mathrm{\eta} 2=.32$. Participants whose partners knew their HIV status $(\mathrm{M}=4.38)$ rated SPOUSE/PARTNER SUPPORT higher than did those whose partners did not know their status $(\mathrm{M}=2.13)$.

Participants were asked if they knew their partner's HIV status before becoming pregnant; those responding "yes" $(\mathrm{n}=204)$ were compared to those responding "no" $(\mathrm{n}=101)$ and a significant difference was found for SPOUSE/PARTNER SUPPORT, F $(1.303)=30.37, \mathrm{p}<.01, \mathrm{\eta} 2=.09$ ). Those who knew their partner's HIV status before becoming pregnant
$(\mathrm{M}=4.45, \mathrm{SD}=.64)$ rated SPOUSE/PARTNER SUPPORT higher than did those who did not know $(\mathrm{M}=3.90, \mathrm{SD}=1.10)$.

Participants who knew their partner's current HIV status (at the time of the survey) $(n=260)$ were compared across the three component scores with those who did not know their partner's status $(n=45)$. Significant differences were found for SPOUSE/PARTNER SUPPORT, $\mathrm{F}(1,303)=62.53, \mathrm{p}<.01, \mathrm{\eta} 2=.17$ and BENEFITS OF DISCLOSE, $\mathrm{F}$ $(1,303)=3.97, \mathrm{p}<.05, \eta 2=.01$. Participants indicating, they knew their partner's status $(\mathrm{M}=4.42, \mathrm{SD}=.68)$ rated SPOUSE/PARTNER SUPPORT higher than those who did not know their partner's status $(\mathrm{M}=3.41, \mathrm{SD}=1.23)$ and those who knew their partner's status $(\mathrm{M}=$ $4.51, \mathrm{SD}=.54)$ also rated BENEFITS OF DISCLOSURE higher than those who did not $(\mathrm{M}=4.33, \mathrm{SD}=.78)$.

A comparison of participants whose family knew their HIV status ( $n=289)$ versus those whose family did not know their status $(n=$ 16) revealed a significant difference on BENEFITS OF DISCLOSURE, $\mathrm{F}(1,303)=39.82, \mathrm{p}<.01, \mathrm{\eta} 2=.12$. Those whose family knew of their status $(\mathrm{M}=4.52)$ rated BENEFITS OF DISCLOSURE higher than did those whose family did not know $(\mathrm{M}=3.65)$.

Participants were also asked whether disclosure of their HIV/ AIDS status to their partner or family impacted their infant feeding decision in a positive $(n=279)$ or negative $(n=23)$ manner. Significant differences in positive versus negative impact were found for SPOUSE/PARTNER SUPPORT, F $(1,302)=4.38, \mathrm{p}<.05, \mathrm{\eta} 2=.03$ and BENEFITS OF DISCLOSURE, $\mathrm{F}(1,302)=26.49, \mathrm{p}<.01, \mathrm{\eta} 2=.15$. Those indicating a positive impact on their infant feeding $(\mathrm{M}=4.30$, $\mathrm{SD}=.83)$ decision rated SPOUSE/PARTNER SUPPORT higher than did those indicating a negative impact $(\mathrm{M}=4.13, \mathrm{SD}=1.02)$ and those indicating a positive impact $(\mathrm{M}=4.45, \mathrm{SD}=.48)$ also rated BENEFITS OF DISCLOSURE higher than did those indicating a negative impact $(\mathrm{M}=4.04, \mathrm{SD}=1.02)$.

\section{Discussion}

With the exception of some mixed responses to items related to breastfeeding, participants were generally very positive in their reactions to the survey items. Participant responses suggested that the clear majority were pleased with having disclosed their HIV status to partners and family. As a result of their disclosure, they benefitted by being able to more openly seek help and advice and, additionally, found infant feeding to be less challenging. Over $94 \%$ of participants had disclosed their HIV status to both family and spouses or partners and the great majority viewed this as a positive and helpful decision. This finding lends support to the advice of experts who recommend disclosure to appropriate others in the mother's life [12]. Participants were also very positive concerning the support they received from their spouses and family, including their infant feeding and testing decisions. It may be that the high level of spouse and family support was due, at least in part, to participants having been open and honest about their HIV status. Alternatively, it may simply be easier for mothers to disclose their HIV status to spouses and family that are more supportive.

The vast majority of participants were very positive about the medical advice they had received. Though still a majority, fewer participants indicated that they had changed their breastfeeding pattern due to medical advice. While expressing overall confidence and satisfaction with medical advice, it may be that many of the mothers had already made their infant feeding decision before consulting with medical personnel. Within the infant feeding category, participants clearly indicated their desire to make informed decisions regarding 
feeding and their belief that their baby was healthy due to making the best feeding decision. The vast majority of participants also indicated that social stigma fears did not make it difficult to formula feed their baby. The fact that social stigma did not appear to be a major factor in feeding decisions for these mothers is encouraging since past research has often indicated that social stigma is a major issue that affects the quality of life for HIV positive individuals in Sub-Saharan Africa $[8,13]$. Participants were mixed in their assessments of whether or not it was safe to breastfeed their child with a slightly greater number indicating that breastfeeding was not safe. The fear of transmitting HIV to their child through breastfeeding is likely the reason why almost twice as many mothers in this study chose formula feeding over breastfeeding.

Participants' ratings of clinic services indicated that they found guidelines provided by the clinic to be useful, that their clinic was supportive, and that they felt safe seeking help. A smaller majority indicted that the clinic helped them to make breastfeeding safer for their child. Overall, participants were very positive concerning the services provided by the clinic that served them. Within the child testing category, with few exceptions, participants indicated that they were motivated to have their child tested for HIV in order to keep their child safe. The majority of participants indicated that they were not scared to have their baby tested for HIV. However, almost a third of the mothers agreed that they were afraid to have their baby tested and this may account, at least in part, for the reason why almost onefifth of the mothers in this study had not had their baby tested for HIV. Since infant testing is critical for the proper care and treatment of HIV positive babies, it would seem important to directly address mothers' fears of infant testing during supportive counselling sessions.

Overall, participants were very positive in response to the items included in the six survey categories. However, participants were often less positive in their ratings of items related to infant feeding and particularly their ratings of items related to breastfeeding. This suggests that some of the mothers in this study were conflicted concerning their choice of infant feeding methods which is not surprising given the fact that there are benefits and risks attached to both breastfeeding and formula feeding. Research findings have indicated that breastfeeding increases the possibility of transmitting HIV to the child but also lowers the risk of malnutrition and certain diseases, especially in resource poor areas where formula cost, clean water, and other factors can be obstacles to proper feeding $[14,15]$. Formula feeding carries less risk of transmitting the HIV virus to infants but also involves a higher risk of infant deaths due to diarrhoea, malnutrition, and other diseases. Prior to 2010 the World Health Organization (WHO) recommended breastfeeding only in resource poor settings with mothers continuing on ART treatment throughout the breastfeeding period until the infant is twelve months old. However, in 2010 WHO recommendations changed to favour breastfeeding along with mothers continuing on ART treatment throughout a six-month exclusive breastfeeding period (WHO, UNAIDS, UNICEF, UNFPA, 2010). Given the pros and cons of either formula or breastfeeding and the changing WHO recommendations, it is not surprising that some mothers experience fear and confusion concerning their feeding choice. Although neither feeding choice guarantees infant safety, it seems important for counsellors and medical advisors to clearly explain the dangers and risks to mothers as well as the current WHO recommendations in order to help mothers make the best choice for themselves and their children and to hopefully reduce the mother's anxiety level [16-19].

\section{Discussion of component score results}

The mean values for the three component scores ranged from 4.27 to 4.51 on the 5-point scale. This indicates that participants, overall, were quite satisfied with the clinic and medical advice they received, believed they received a high level of support from their spouse or partner, and believed that it was beneficial to have disclosed their HIV status to family and spouse or partner.

There were several significant findings relating demographic and related variables to the three component scores that emerged from the Principal Component Analysis. Participants who indicated their pregnancy was wanted were more positive concerning their spouse/ partner support and the benefits of disclosing their HIV status than were those who indicated their pregnancy was not wanted. It may be that wanted pregnancies were more likely to have been planned and tended to represent a mutual decision by the mother and her spouse/partner. This, in turn might facilitate more open and honest communication and responsibility sharing between the partners as well as with other close family members. Additionally, an unwanted pregnancy may have brought up issues that were not dealt with in advance, such as financial burdens, housing arrangements, childcare, etc. Such issues might lead the spouse/partner to be less happy about the pregnancy and, thus, less likely to be supportive of the mother.

Participants who began ARV treatment before becoming pregnant were more positive about spouse/partner support than were those who began treatment after becoming pregnant. A possible explanation is that mothers and their spouses/partners, in situations where ARV treatment was begun before the pregnancy, were less fearful and more confident about the baby's HIV status and this led to a more relaxed and supportive relationship.

Participants who were very or extremely sure about taking their HIV medications as directed reported a higher level of satisfaction with the medical and clinic advice they received, higher levels of spouse/ partner support, and greater benefits from disclosing their HIV status than did those less sure about taking their medications as directed. There does not appear to be an easy explanation for this finding that would fit all or most participants. Any number of factors could affect the participant's adherence to medication recommendations such as not accepting the reality of being HIV positive, depression, severe anxiety, lack of control in one's life, lack of needed resources, etc. Any of these factors, if present, could lead to lack of adherence to medication recommendations as well as the quality of relationships with medical or clinic personnel, spouse/partner, and family.

Participants whose partners knew of their HIV status reported greater spouse/partner support than did those whose partners did not know of their status though it should be noted that only 15 participants indicated that their partners did not know of their status. A possible explanation is that participants who did not share their status with their spouse/partner were not in the types of close and open relationships that engender the full support of their partners. Alternatively, some of these participants may have been in less committed or shorter-term relationships and feared sharing their HIV status; a situation that could well lead to less partner support.

Participants who knew their partner's HIV status before becoming pregnant reported a higher level of spouse/partner support than did those who did not know of their partner's status before becoming pregnant. Participants were also asked if they knew about their partner's current (at the time of the survey) HIV status. Those who knew of their partner's current status indicated that they received higher levels of spouse/partner support as well as higher levels of benefit from disclosure of their own status. This difference may have occurred because participants in close and more open relationships were more 
likely to know of their partner's status and also more likely to benefit from their own disclosure and/or receive support from their partner within this type of relationship.

Participants whose family members knew of their HIV status indicated greater benefits from disclosure than did those whose family did not know of their status. Participants who did not disclose to their family could obviously not benefit from disclosure to family members; however, they may have disclosed to others and still have perceived benefits from such disclosure. Still it appears that participants who did not disclose to their families may have given up some level of benefits that they might otherwise have received.

Participants who indicated that disclosure of their HIV status to their partner or family impacted their infant feeding decision in a positive manner also reported a higher level of spouse/partner support and greater benefits from having disclosed than did those who indicated a negative impact on their feeding decision. This finding suggests that the reaction of the spouse/partner and family members to the mother's disclosure of her HIV status can have an important impact on the infant feeding decision and likely on other areas of the mother's quality of life. The infant feeding choice is a very important factor in keeping the child safe and counsellors and medical personnel should be aware of mothers dealing with negative spouse/partner or family influences and help the mother deal with these influences in an effective manner. With some mothers it might be wise to consider couple or family counselling to help resolve such issues.

\section{Limitations of the Study}

Study participants were recruited from six Botswana districts, all with high HIV prevalence rates for women of reproductive age. Thus, the results of this study may not generalize to all of the PMTCT programs throughout Botswana. Additionally, all participants were volunteers rather than randomly selected respondents and participants with particularly positive or negative views of their experience may have been more inclined to volunteer. Because of such limitations, caution should be exercised in generalizing the findings beyond the sample of participants surveyed.

\section{Summary and conclusions}

With the exception of some items related to breastfeeding, participants were quite positive concerning their reactions to all of the survey categories as well as the three component scores. This indicates that participants were generally happy with the consequences of having disclosed their HIV status to family members and spouses/partners, the support they received from family members and spouses/partners, the quality of the medical advice they received, their chosen infant feeding method, the quality of clinic services, and child testing.

Reactions to breastfeeding were more mixed with almost equal numbers of mothers agreeing and disagreeing that that it was safe to breastfeed their child. Given current WHO recommendations favouring breastfeeding as the safest alternative for keeping the children of HIV positive mothers safe [16], this is an area where medical advice and counselling may be particularly important. Because many of the mothers in this study viewed breastfeeding as unsafe for their child, these mothers may automatically choose formula feeding. It is likely that some mothers viewed breastfeeding as unsafe because of past recommendations that favoured formula feeding except for mothers in resource poor areas. Therefore, it is particularly important for medical personnel and counsellors to carefully review with mothers the recommendation that favours breastfeeding and the rationale for this recommendation. While the infant feeding choice is ultimately the mother's decision, it is critical that mothers be prepared to make fully informed decisions rather than relying on past feeding practices.

Ratings for the three component scores of the study indicated that participants were generally very satisfied with the clinic and medical advice they received, with the level of spouse/partner support, and with the beneficial consequences resulting from disclosure of their HIV status to family members and spouses/partners. Their satisfaction in these areas tended to be highest when their pregnancy was wanted, when ARV treatment was begun before becoming pregnant, when ARV medication was taken as directed, when their partners were aware of the mother's HIV status, when mothers were aware of their partners HIV status, when their family was aware of their HIV status, and when mothers viewed their family and spouses/partners as having a positive impact on the infant feeding decision.

It seems particularly important that the vast majority of participants appeared to benefit a great deal when they were open and honest with their family and spouse/partner about their HIV status and when they were also aware of their spouse's/partner's HIV status. The vast majority of participants reported that they had shared their HIV status with their family and/or spouses. However, a small number indicated that they had not disclosed their status. It would seem important for counsellors to become aware of whether or not mothers have disclosed their status to significant others. For mothers who have not disclosed, it would be helpful to explore whether their nondisclosure is due to their own fear or embarrassment or due to a realistic fear of the reactions of their family members or spouses/partners. In some cases, nondisclosure might be the best course of action with family and/or partners; however, in other cases the mother may be foregoing many benefits because of their own shame or embarrassment.

The major goal of PMTCT programs is supporting mothers to assist them in having healthy babies. For this study only 5 (2.8\%) of the 178 babies tested were HIV positive which is slightly below the reported rate of 3-4\% for Botswana (Assessment Report, SADC Region, 2015). Due to the small number of HIV positive babies in this study, formal statistical analysis of factors related to babies being HIV positive or negative was not warranted. However, data were reviewed to determine if all five or at least four of the five HIV positive infants fell within a particular category of selected demographic and related variables of the study. No meaningful pattern was found related to mothers' level of education, whether the pregnancy was wanted or not wanted, whether ARV treatment was begun before or after becoming pregnant, whether or not the mother was sure about taking her medications as directed, or the infant feeding choice. All five positive infants were born to mothers who had disclosed their HIV status to their partners and this was also true for those who had disclosed to their family member; however, these findings are not surprising due to the fact that almost all mothers had disclosed to their partners and family. Four of the five HIV positive infants were born to mothers who indicated they were cohabitating and this may be worth future study to determine if this finding was due to random chance (since the vast majority of cohabitating mothers did not have HIV positive babies) or if something about the cohabitating relationship is associated with giving birth to HIV positive babies.

\section{References}

1. Douglas GC, King BF (1992). Maternal-fetal transmission of human immunodeficiency virus: a review of possible routes and cellular mechanisms of infection. Clin Infect Dis., 15: 678-691. [Crossref]

2. De Cock KM, Fowler MG, Mercier E, de Vincenzi I, Saba J, et al. (2000) Prevention of mother-to-child HIV transmission in resource-poor countries: translating research into policy and practice. JAMA 283: 1175-1182. [Crossref] 
3. Nduati R, John G, Mbori-Ngacha D, Richardson B, Overbaugh J, et al. (2000) Effect of breastfeeding and formula feeding on transmission of HIV-1: a randomized clinical trial. JAMA 283: 1167-1174. [Crossref]

4. Magoni M, Bassani L, Okong P, Kituuka P, Germinario EP, et al. (2005) Mode of infant feeding and HIV infection in children in a program for prevention of mother-to-child transmission in Uganda. AIDS 19: 433-437. [Crossref]

5. Oladokun RE, Brown BJ, Osinusi K (2010). Infant-feeding pattern of HIV-positive women in a prevention of mother-to-child transmission (PMTCT) programme. AIDS care, 22: 1108-1114. [Crossref]

6. Ndubuka J, Ndubuka N, Li Y, Marshall CM, Ehiri J (2013). Knowledge, attitudes and practices regarding infant feeding among HIV-infected pregnant women in Gaborone, Botswana: a cross-sectional survey. BMJ open, 3: e003749. [Crossref]

7. Poggensee G, Schulze K, Moneta I, Mbezi P, Baryomunsi C, et al. (2004). Infant feeding practices in western Tanzania and Uganda: implications for infant feeding recommendations for HIV-infected mothers. Trop Med Int Health, 9: 477-485. [Crossref]

8. Doherty T, Chopra M, Nkonki L, Jackson D, Greiner T (2006) Effect of the HIV epidemic on infant feeding in South Africa: "When they see me coming with the tins they laugh at me". Bull World Health Organ 84: 90-96. [Crossref]

9. Stockton R, Paul T, Morran DK, Yebei PK, Chang SH, et al. (2012). A survey of HIV/AIDS counselors in Botswana: Satisfaction with training and supervision, selfperceived effectiveness and reactions to counseling HIV-positive clients. Journal of HIV/AIDS \& Social Services, 11: 424-446.
10. Medley A, Garcia-Moreno C, McGill S, Maman S. (2004). Rates, barriers and outcomes of HIV serostatus disclosure among women in developing countries: implications for prevention of mother-to-child transmission programmes. Bull World Health Organ, 82: 299-307. [Crossref]

11. Tabachnick BG, Fidell LS (2007). Using multivariate statistics. Allyn \& Bacon/Pearson Education.

12. Pennebaker JW, Colder M, Sharp LK (1990) Accelerating the coping process. J Pers Soc Psychol 58: 528-537. [Crossref]

13. Thairu LN, Pelto GH, Rollins NC, Bland RM, Ntshangase N (2005). Sociocultural influences on infant feeding decisions among HIV-infected women in rural Kwa-Zulu Natal, South Africa. Matern Child Nutr, 1: 2-10. [Crossref]

14. John-Stewart G, Mbori-Ngacha D, Ekpini R, Janoff EN, Nkengasong, J, et al. (2004) Breast-feeding and transmission of HIV-1. J Acquir Immune Defic Syndr 35: 196.

15. Sint TT, Lovich R, Hammond W, Kim M, Melillo S, et al. (2013) Challenges in infant and young child nutrition in the context of HIV. AIDS 27 Suppl 2: S169-177. [Crossref]

16. Guidelines on HIV and infant feeding, WHO, UNAIDS, UNICEF, UNFPA (2010) https://www.unicef.org/nutrition/files/HIV_and_IF_guidelines_and_summary_of evidence_2010.pdf

17. Ministry of Health, PMTCT Program Data, 2015.

18. New data on the prevention of mother to child transmission of HIV and their policy implications. WHO, UNICEF, UNAIDS; 2000.

19. Ross JS, Piwoz EG, Habicht JP (2004) Is breastfeeding best for HIV-positive mothers? AIDS 18: 363. [Crossref]

Copyright: (C2018 Stockton R. This is an open-access article distributed under the terms of the Creative Commons Attribution License, which permits unrestricted use, distribution, and reproduction in any medium, provided the original author and source are credited. 